\title{
Dual-layer spectral detector CT to study the correlation between pericoronary adipose tissue and coronary artery stenosis
}

\author{
Xiaolong Zhu ${ }^{1,2}$, Xujiao Chen ${ }^{1}$, Shaowei Ma ${ }^{1}$, Ke Zhou ${ }^{1}$ and Yang Hou ${ }^{1 *}$
}

\begin{abstract}
Background: To investigate the relationship of pericoronary adipose tissue (PCAT) with coronary artery stenosis using dual-layer spectral detector CT (SDCT).

Methods: 99 patients were retrospectively divided into normal group, non-significant stenosis group and significant stenosis group ( $n=33$ in each group). Fat attenuation index (FAl) 40kev, spectral curve slope ( $\lambda H U$ ), effective atomic number (Eff-Z) and epicardial fat volume (EFV) were quantitatively evaluated of the narrowest part of the lesion tissue by SDCT.

Results: There were significant differences in PCAT parameters on SDCT (FAI40keV, $\lambda H U$, Eff-Z and EFV) among the three groups $(P<0.05)$. FAl40keV, $\lambda \mathrm{HU}$, and Eff-Z in significant stenosis group were statistically different from those in normal group and non-significant stenosis group $(P<0.05)$. FAl40keV, $\lambda \mathrm{HU}$, and Eff-Z in non-significant stenosis group were statistically different from significant stenosis group $(P<0.05)$. EFV in normal group were significantly lower in non-significant stenosis group and significant stenosis group $(P<0.001)$. Univariate and multivariate logistic regression analyses identified FAI40keV (OR $=1.50,95 \% \mathrm{Cl} 1.01$ to 1.09) and $\lambda \mathrm{HU}(\mathrm{OR}=6.81,95 \% \mathrm{Cl} 1.87$ to 24.86) as independent predictors of significant stenosis. FAI40keV and $\lambda \mathrm{HU}$ had quite good discrimination, with an AUC of 0.84 and 0.80 respectively.

Conclusion: FAl40keV, $\lambda \mathrm{HU}$, and Eff-Z on SDCT in significant stenosis group were significantly different from normal and non-significant stenosis group while EFV in normal group were significantly different from non-significant stenosis group and significant stenosis group. FAI40kev and $\lambda H U$ were risk factors for significant stenosis.
\end{abstract}

Keywords: Dual-layer spectral detector, Pericoronary adipose tissue, Epicardial fat volume, Coronary artery stenosis, Plaque

\section{Background}

Coronary artery disease (CAD) is one of the leading causes of death in the world [1]. As well known, the epicardial adipose tissue (EAT) has endocrine functions and

*Correspondence: houyang1973@163.com

1 Department of Radiology, Key Laboratory of Intelligent Computing in Medical Image, Ministry of Education, Shengjing Hospital of China Medical University, No.36, Sanhao Street, Heping District, Shenyang 110004, Liaoning, People's Republic of China

Full list of author information is available at the end of the article shares the microenvironment with the coronary artery. Magnetic resonance imaging (MRI) and multi-slice spiral CT (MSCT) have been used to evaluate EAT, especially the application of MSCT. MSCT quantitative epicardial fat volume (EFV) is an important predictor of coronary heart disease and cardiovascular events, which is also very important for formulating follow-up treatment plans $[2,3]$.

The EAT surrounding the coronary artery is called pericoronary adipose tissue (PCAT), which has been associated with CAD and major cardiovascular events original author(s) and the source, provide a link to the Creative Commons licence, and indicate if changes were made. The images or other third party material in this article are included in the article's Creative Commons licence, unless indicated otherwise in a credit line to the material. If material is not included in the article's Creative Commons licence and your intended use is not permitted by statutory regulation or exceeds the permitted use, you will need to obtain permission directly from the copyright holder. To view a copy of this licence, visit http://creativecommons.org/licenses/by/4.0/. The Creative Commons Public Domain Dedication waiver (http://creativeco mmons.org/publicdomain/zero/1.0/) applies to the data made available in this article, unless otherwise stated in a credit line to the data. 
[4]. Pericoronal fat attenuation index (FAI) is a marker of coronary artery wall inflammation. Antonopoulos et al. [5] proposed that the vessel-derived inflammatory cytokine of PCAT can inhibit the differentiation of human preadipocytes in a paracrine manner and reflect the balance between the lipid and water phase of adipose tissue through FAI, and then reflect the degree of adipocyte differentiation. These findings support the notion that vessel-derived inflammatory cytokines inhibit lipid accumulation in PVAT by inducing the proliferation and inhibiting the differentiation of human preadipocytes in a paracrine manner. Therefore, we hypothesized that noninvasive imaging tools, capable of monitoring these phenotypic changes of PVAT driven by the underlying vascular inflammation, could be used to identify vascular inflammation in human coronary arteries.

Therefore, inflammation can be quantified using FAI. Evaluation of the degree of atherosclerosis and the state of pericoronary fat can help reveal the role of inflammation in the formation and development of atherosclerosis. Although both FAI and EFV are closely related to atherosclerosis, there is no comparison between the two indicators and the degree of lumen stenosis.

Energy CT can identify material components, and the structure of different components can reflect the significant difference in attenuation, atomic number and spectral curve, therefore it may reflect the pathophysiological function of the tissue [6]. Dual-layer spectral detector CT (SDCT) has emerged as a new energy $\mathrm{CT}$ with potential to improve the ability to detect tissue characterization. Compared with traditional techniques, effective atomic number based on SDCT can improve the diagnostic performance of coronary artery plaque analysis [7]. In theory, the index of PCAT based on SDCT may be more sensitive than that of MSCT in reflecting the inflammation of PCAT.

This study aims to explore the correlation between PCAT parameters and different degrees of coronary artery stenosis based on SDCT and to provide early warning and early effective treatment for the development of coronary atherosclerosis.

\section{Materials and methods}

\section{General information}

99 patients who underwent coronary computed tomography angiography (CTA) using SDCT for CAD between May 2019 and September 2019 at Shengjing Hospital of China Medical University were retrospectively included. 33 consecutive patients with coronary diameter stenosis (DS) $\geq 50 \%$ were retrospectively included and defined as significant stenosis group. 33 patients with coronary DS $<50 \%$ and 33 patients without coronary stenosis during the same time period at a ratio of 1:1:1 were included and defined as non-significant stenosis group and control group, respectively.

Inclusion criteria were patients with good CTA image quality (good blood vessel display, clear borders, no respiratory and heartbeat artifacts, no step artifacts). Exclusion criteria were patients (1) with high-risk plaque on CTA; (2) with history of malignancy, acute infection or fever; and (3) with history of cardiac surgery. The study was approved by the ethics committee of Shengjing Hospital of China Medical University (2020PS231K) and all patients signed the written informed consent for examination.

\section{SDCT acquisition and reconstruction}

All patients underwent coronary CTA examinations on a dual-layer SDCT (IQon spectral CT, Philips Healthcare) using prospective electrocardiogram (ECG)-gated acquisitions (Step \& Shoot Cardiac). The scan parameters were set as follows: The tube voltage was set at $120 \mathrm{kV}$; The tube current automatic modulation technology was used, with the Dose Right Index (DRI) of 13; the field of view was $250 \mathrm{~mm}$, the tube rotation time was $0.27 \mathrm{~s}$; the detector collimation was $64 \times 0.625 \mathrm{~mm}$, the display matrix was $512 \times 512$, the rotation speed was $0.27 \mathrm{~s}$, and the detector collimation was $64 \times 0.625 \mathrm{~mm}$. The scan trigger was centered around a physiologic cardiac phase of ventricular diastasis corresponding to $78 \%$ of the $R-R$ interval with $a \pm 3 \%$ buffer. Automatic bolus tracker was used with a region of interest (ROI) in the ascending aorta at the level of pulmonary artery. The scans were initiated under full inspiration $6 \mathrm{~s}$ after a pre-determined signal attenuation threshold of $150 \mathrm{HU}$ were attained. Contrast media (Visipaque Iodixanol 270; GE Healthcare, Ireland) was injected intravenously through the antecubital vein using an 18-gauge catheter dual-tube high pressure syringe (Ulrich REF XD 2051). Contrast media was used individually according to body weight. The total amount of contrast media $=$ patient weight ${ }^{*} 0.8 \mathrm{~mL} / \mathrm{kg}$. Contrast injection flow rate $(\mathrm{mL} / \mathrm{s})=$ total amount $(\mathrm{mL}) /$ injection time (12 s), followed by injection of $30 \mathrm{~mL}$ of saline at the same injection rate. Prior to CT examination, patients with a heart rate $(\mathrm{HR})>75 \mathrm{bpm}$ received a $\beta$-receptor blocker 25-50 mg (Metoprolol Succinate sustained-release tablets, AstraZeneca, Sweden) orally to reduce and stabilize $\mathrm{HR}$.

Spectral reconstruction algorithm (Spectral level 4, Philips Healthcare) were adopted for image reconstruction. The convolution function was CS, with a reconstruction layer thickness of $0.9 \mathrm{~mm}$ and interval of $0.45 \mathrm{~mm}$. After the spectral-based image (SBI) were reconstructed, the above image was transmitted to IntelliSpace Protal (Version 6.5, Philips Healthcare) for post-processing. 


\section{Coronary CTA analysis}

The coronary artery segment was divided into $17 \mathrm{seg}$ ments according to the American Heart Association guidelines for coronary artery segmentation [8], and the degree of coronary artery stenosis was measured by image processing software and visual inspection: normal (no stenosis), no significant stenosis (diameter stenosis (DS) $<50 \%$ ) and significant stenosis(DS $\geq 50 \%$ )[9]. Plaques were classified as noncalcified plaques (without any calcium), calcified plaques and mixed plaques (the calcified volume within the plaques $\leq 50 \%$ ) [10].

\section{Parameters of EAT quantification}

The PCAT parameters around the most significant stenosis were measured and analyzed in significant stenosis group and non-significant stenosis group. In the normal group, PCAT parameters were measured at $40 \mathrm{~mm}$ proximal to the right coronary artery (RCA) and the radial distance from the outer vessel wall is equal to the diameter of the target vessel. The whole (average) plaque burden of patients with plaques was $57.47 \%$. The FAI on $40 \mathrm{keV}$ virtual mono-energetic images (VMI) (FAI40keV), the slope of the energy spectrum curve $(\lambda \mathrm{HU})$, and the effective atomic number (Eff-Z) were obtained. FAI was defined as the mean CT attenuation of adipose tissue, which was within a radial distance from the outer vessel wall equal to the diameter of the target vessel [11], and the length covers the 3-dimensional volume of the entire lesion. The attenuation value of PCAT around the narrowest part of the blood vessel with a constant ROI of $20 \mathrm{~mm}^{2}$ in the axial position was measured. The composition in the range of polychromatic images -190 to $-30 \mathrm{HU}$ is considered as the fat threshold, and we take an integer as the attenuation threshold on VMI at $40 \mathrm{kev}$ and $70 \mathrm{kev}$. The relative EAT attenuation levels between VMI at $40 \mathrm{kev}$ and $70 \mathrm{kev}$ levels were 1.44 and 0.90 , respectively [12]. Therefore $-280 \mathrm{HU}$ to $-40 \mathrm{HU}$ and $-170 \mathrm{HU}$ to $-30 \mathrm{HU}$ were applied to identify adipose tissue voxels in VMI at $40 \mathrm{keV}$ and $70 \mathrm{keV}$ respectively. Measure and calculate PCAT attenuation in VMI at $40 \mathrm{keV}$ (FAI$40 \mathrm{keV}$ ) and subcutaneous fat (SAT), $\lambda \mathrm{HU}=\mathrm{y} / \mathrm{x}, \mathrm{y}$ means the difference of absolute value of PCAT attenuation corresponding to $40 \mathrm{keV}$ and $70 \mathrm{keV}$ single level, $\mathrm{x}$ value is fixed at 30 . Take the average of the three measurements.

EFV was defined as the volume of all adipose tissue surrounded by pericardium (Fig. 1) and EFV was measured on a conventional polychromatic images. Analysis was independently evaluated by two experienced radiologists (with a 5-year or an 8-year experience of coronary CTA). Take the average of the two as the final measured value. EFV was semi-automatically measured using the software (Heart Disease Risk Assessment Version 1.2.0, Siemens Healthineer, Germany) and manually adjusted if necessary. With the bifurcation of the pulmonary artery as the upper boundary and the level of the descending artery as the lower boundary of the heart, EFV were automatically calculated by including contiguous threedimensional fat voxels within the range of -190 to $-30 \mathrm{HU}$ enclosed by the visceral pericardium [13].

\section{Coronary angiography (CAG)}

Patients in significant stenosis group received CAG, and patients in non-significant stenosis group and normal group did not receive CAG. The severity of coronary

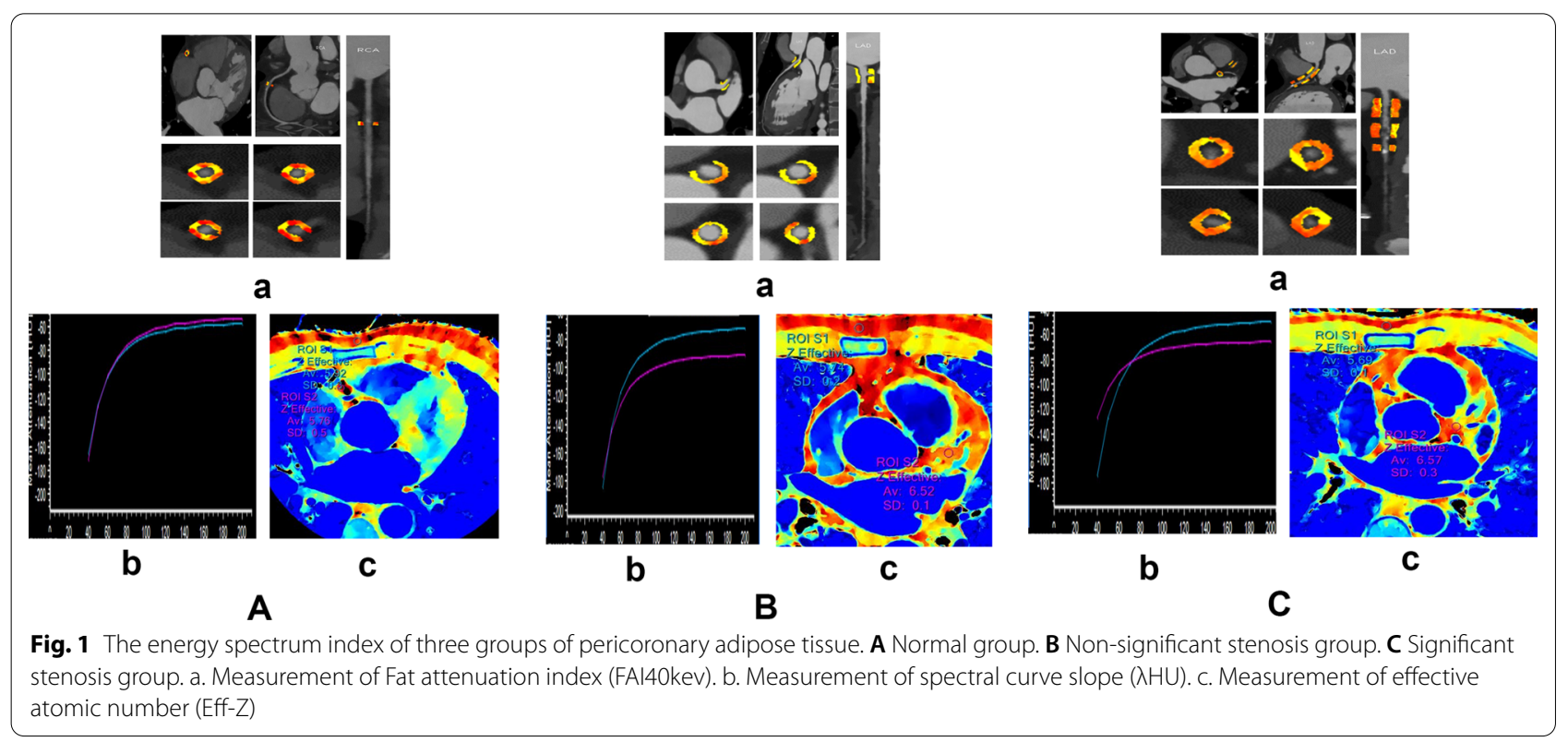


artery disease was determined by CAG. CAG was performed according to standard techniques and at least two views in different planes were obtained for each coronary artery. The images with the most severe stenosis were captured and the severity of coronary stenosis was evaluated by one experienced observer who was aware of the patients' clinical history but blinded to the results from coronary CTA evaluated all angiograms with regard to the presence (diameter reduction $\geq 50 \%$ ).

\section{Statistical analysis}

All data analysis was performed using SPSS. 20.0 (IBM, Armonk, NY) and SAS 9.4 (IBM, Armonk, NY). Quantitative data were described as mean \pm standard deviation (SD). Categorical variables were presented as numbers (percentage). Multivariate analysis of variance and Duncan multiple range test were used to compare the basic information of the three groups. Multiple linear regression analysis was performed to evaluate the relationship between FAI40keV, $\lambda \mathrm{HU}$, Eff-Z, EFV and the significant stenosis. Z-test was used to compare the AUC between models. $P<0.05$ was considered statistically significant.

\section{Results}

\section{Baseline information}

There were no significant difference in age, gender, BMI, hypertension, diabetes, smoking, family history of coronary heart disease, cholesterol, medicine, the narrowest lesion location and the narrowest lesion plaque among the three groups $(P>0.05)$ (Table 1$)$.

\section{Comparison of PCAT parameters on SDCT in three groups}

The reproducibility of FAI measurements was good, and the Kappa value of intro-observer agreements was 0.848 (95\% CI, 0.748 0.952, $P<0.001$ ). As shown in Table 2, there were significant differences in PCAT parameters on SDCT (FAI40keV, $\lambda \mathrm{HU}, \mathrm{Eff}-\mathrm{Z}$ and EFV) among the three groups $(P<0.05)$. The indexes of PCAT (FAI40keV, $\lambda H U$, and Eff-Z) in significant stenosis group were statistically different from those in normal group and nonsignificant stenosis group $(P<0.05)$. The indexes of PCAT (FAI40keV, $\lambda \mathrm{HU}$, and Eff-Z) in non-significant stenosis group were statistically different from those in significant stenosis group $(P<0.05)$. The EFV in normal group were

Table 1 Baseline data of patients

\begin{tabular}{|c|c|c|c|c|}
\hline Characteristics & $\begin{array}{l}\text { Normal group } \\
(n=33)\end{array}$ & $\begin{array}{l}\text { Non-significant stenosis } \\
\text { group } \\
(n=33)\end{array}$ & $\begin{array}{l}\text { Significant stenosis group } \\
(\mathrm{n}=33)\end{array}$ & $P$ value \\
\hline Age & $53.12 \pm 8.33$ & $55.73 \pm 6.80$ & $56.82 \pm 9.41$ & 0.297 \\
\hline Gender (Male, n, \%) & $14(42.42)$ & $21(63.64)$ & $24(72.73)$ & 0.326 \\
\hline $\mathrm{BMl}$ & $23.78 \pm 4.35$ & $25.44 \pm 5.12$ & $25.43 \pm 6.43$ & 0.124 \\
\hline Hypertension (n, \%) & $17(51.52)$ & $21(63.64)$ & $22(66.67)$ & 0.215 \\
\hline Diabetes (n, \%) & $9(27.27)$ & $13(39.39)$ & $15(45.45)$ & 0.413 \\
\hline Smoking (n, \%) & $11(33.33)$ & $18(54.55)$ & $17(51.52)$ & 0.158 \\
\hline Family history of CHD (n, \%) & $8(24.24)$ & $9(27.27)$ & 13(39.39) & 0.594 \\
\hline HDL cholesterol & $1.05 \pm 0.87$ & $0.99 \pm 0.76$ & $0.92 \pm 0.81$ & 0.252 \\
\hline LDL cholesterol & $2.54 \pm 0.67$ & $2.91 \pm 0.83$ & $3.26 \pm 0.78$ & 0.127 \\
\hline Total cholesterol & $4.18 \pm 0.48$ & $4.59 \pm 0.62$ & $4.91 \pm 0.43$ & 0.234 \\
\hline Triglyceride & $1.62 \pm 0.32$ & $2.08 \pm 0.48$ & $2.45 \pm 0.51$ & 0.211 \\
\hline \multicolumn{5}{|l|}{ Medicine } \\
\hline Aspirin & $31(93.94)$ & $33(100)$ & $33(100)$ & 0.761 \\
\hline Statins & $22(66.67)$ & $31(93.94)$ & $33(100)$ & 0.436 \\
\hline \multicolumn{5}{|l|}{ The narrowest lesion location } \\
\hline $\operatorname{LAD}(\mathrm{n}, \%)$ & & $24(72.73)$ & $28(84.85)$ & \\
\hline $\mathrm{RCA}(\mathrm{n}, \%)$ & & $7(21.21)$ & $4(12.12)$ & \\
\hline $\operatorname{LCX}(n, \%)$ & & $1(3.03)$ & $1(3.03)$ & \\
\hline $\operatorname{LM}(n, \%)$ & & $1(3.03)$ & $0(0)$ & \\
\hline \multicolumn{5}{|l|}{ The narrowest lesion plaque } \\
\hline Non-calcified & & $8(24.24)$ & $9(27.20)$ & \\
\hline Calcified plaque & & $11(33.33)$ & $4(12.10)$ & \\
\hline Mixed & & $14(42.40)$ & $20(60.60)$ & \\
\hline
\end{tabular}

$\mathrm{BMI}=$ body mass index; $\mathrm{CHD}=$ coronary heart disease; $\mathrm{LM}=$ left main coronary artery; $\mathrm{LAD}=$ left anterior descending artery; $\mathrm{LCX}=$ left circumflex artery; $\mathrm{RCA}=$ right coronary artery, $\mathrm{HDL}=$ high-density lipoprotein, $\mathrm{LDL}=$ low-density lipoprotein. $P<0.05$ was considered statistically significant 
Table 2 Quantification of PCAT parameters in three groups

\begin{tabular}{llllrr}
\hline & $\begin{array}{l}\text { Normal group } \\
(\mathbf{n}=\mathbf{3 3})\end{array}$ & $\begin{array}{l}\text { Non-significant stenosis } \\
\text { group } \\
(\mathbf{n}=\mathbf{3 3})\end{array}$ & $\begin{array}{l}\text { Significant stenosis group } \\
(\mathbf{n}=\mathbf{3 3})\end{array}$ & F value & P value \\
\hline $\mathrm{FAl}_{40 \mathrm{keV}}$ & $-168.73 \pm 34.17$ & $-161.63 \pm 36.31^{\#}$ & $-127.22 \pm 33.28^{*}$ & 24.78 & 0.003 \\
$\lambda_{\mathrm{HU}}$ & $1.89 \pm 0.92$ & $1.96 \pm 1.17^{\#}$ & $1.18 \pm 0.83^{*}$ & 21.73 & 0.004 \\
$\mathrm{Eff}-\mathrm{Z}$ & $6.15 \pm 0.64$ & $6.13 \pm 0.56^{\#}$ & $6.61 \pm 0.61^{*}$ & 18.34 & 0.005 \\
$\mathrm{EFV}$ & $102.11 \pm 35.59^{\&}$ & $129.17 \pm 39.78$ & $140.06 \pm 35.50^{*}$ & 20.28 & 0.004 \\
\hline
\end{tabular}

Compared with non-significant stenosis group, ${ }^{\&} P<0.05$; compared with significant stenosis group, ${ }^{\#} P<0.05$; compared with normal group, ${ }^{*} P<0.05$

PCAT $=$ pericoronary adipose tissue

significantly lower than those in non-significant stenosis group and significant stenosis group $(P<0.001)$.

\section{Relationship between PCAT parameters and significant stenosis}

Variables in Table 2 were assessed in univariate and multivariate logistic regression analyses, which identified FAI40keV $(\mathrm{OR}=1.50,95 \% \mathrm{CI} 1.01$ to 1.09$)$ and $\lambda \mathrm{HU}$ $(\mathrm{OR}=6.81,95 \% \mathrm{CI} 1.87$ to 24.86$)$ as independent predictors of significant stenosis (Table 3).

\section{ROC analysis}

The ROC showed that FAI40keV and $\lambda H U$ had quite good discrimination (Fig. 2), with an AUC of 0.84 and 0.80 respectively (Table 4 ). No significant differences were observed in FAI40keV and $\lambda \mathrm{HU}$ in the prediction for significant stenosis $(P=0.936)$.

\section{Discussion}

In this study, we found that the indexes of PCAT (FAI$40 \mathrm{keV}, \lambda \mathrm{HU}$, and Eff-Z) on SDCT in significant stenosis group were significantly different from those in normal group and non-significant stenosis group while EFV in normal group were significantly different from those in non-significant stenosis group and significant stenosis group. FAI40keV and $\lambda \mathrm{HU}$ are independent predictors of significant stenosis. To the best of our knowledge, this article is the first application of SDCT to study the changes of PCAT parameters at different stages of atherosclerosis.

Vascular inflammation is not only a key factor in the formation of atherosclerotic plaque, but also in triggering the plaque rupture $[14,15]$. There is evidence that the metabolic process of PCAT induces endothelial dysfunction, inflammatory response and smooth muscle cell proliferation, thereby affecting the formation of atherosclerotic plaques [16]. EAT is believed to exert local inflammation and atherosclerosis effects on epicardial coronary arteries through a paracrine mechanism, and is therefore related to the pathogenesis of coronary atherosclerosis $[17,18]$. All stages of atherosclerosis involve the inflammatory process and were accompanied by multiple inflammatory mediators. Compared with conventional CT, SDCT uses X-ray photons of different energies, which can penetrate different materials and produce differential compton effect and photoelectric effect. Due to the difference of atomic $\mathrm{K}$ boundary value, we can get different effective atomic numbers, energy spectrum curves, single-energy images, and can detect differences in constituent substances.

The results of this study showed there were significant differences in SDCT-based PCAT parameters (FAI$40 \mathrm{keV}, \lambda \mathrm{HU}, \mathrm{Eff}-\mathrm{Z}$ and EFV) among the three groups. The indexes of PCAT (FAI40keV, $\lambda \mathrm{HU}$, and Eff-Z) on SDCT in significant stenosis group were significantly different from those in normal group and non-significant stenosis group while EFV in normal group were

Table 3 Odds ratios for significant stenosis (stenosis $\geq 50 \%$ )

\begin{tabular}{|c|c|c|c|c|c|c|}
\hline & \multicolumn{3}{|c|}{ Univariate } & \multicolumn{3}{|c|}{ Multivariate } \\
\hline & $\beta$ & $\mathrm{OR}(95 \% \mathrm{Cl})$ & $P$ value & $\beta$ & OR(95\%Cl) & $P$ value \\
\hline FAl40keV & 0.041 & $1.027(1.001-1.054)$ & 0.042 & 0.037 & $1.496(1.013-1.087)$ & 0.023 \\
\hline$\lambda_{\mathrm{HU}}$ & 0.434 & $2.939(1.283-6.733)$ & 0.011 & 0.561 & $6.813(1.868-24.861)$ & 0.014 \\
\hline Eff $-Z$ & 1.677 & $1.167(0.186-6.942)$ & 0.869 & 0.154 & $0.142(0.133-1.647)$ & 0.183 \\
\hline EFV & 0.032 & $1.016(0.998-1.035)$ & 0.075 & 0.016 & $1.004(0.998-1.009)$ & 0.503 \\
\hline
\end{tabular}

$\mathrm{OR}=$ Odds ratio $\mathrm{Cl}=$ confidence interval 


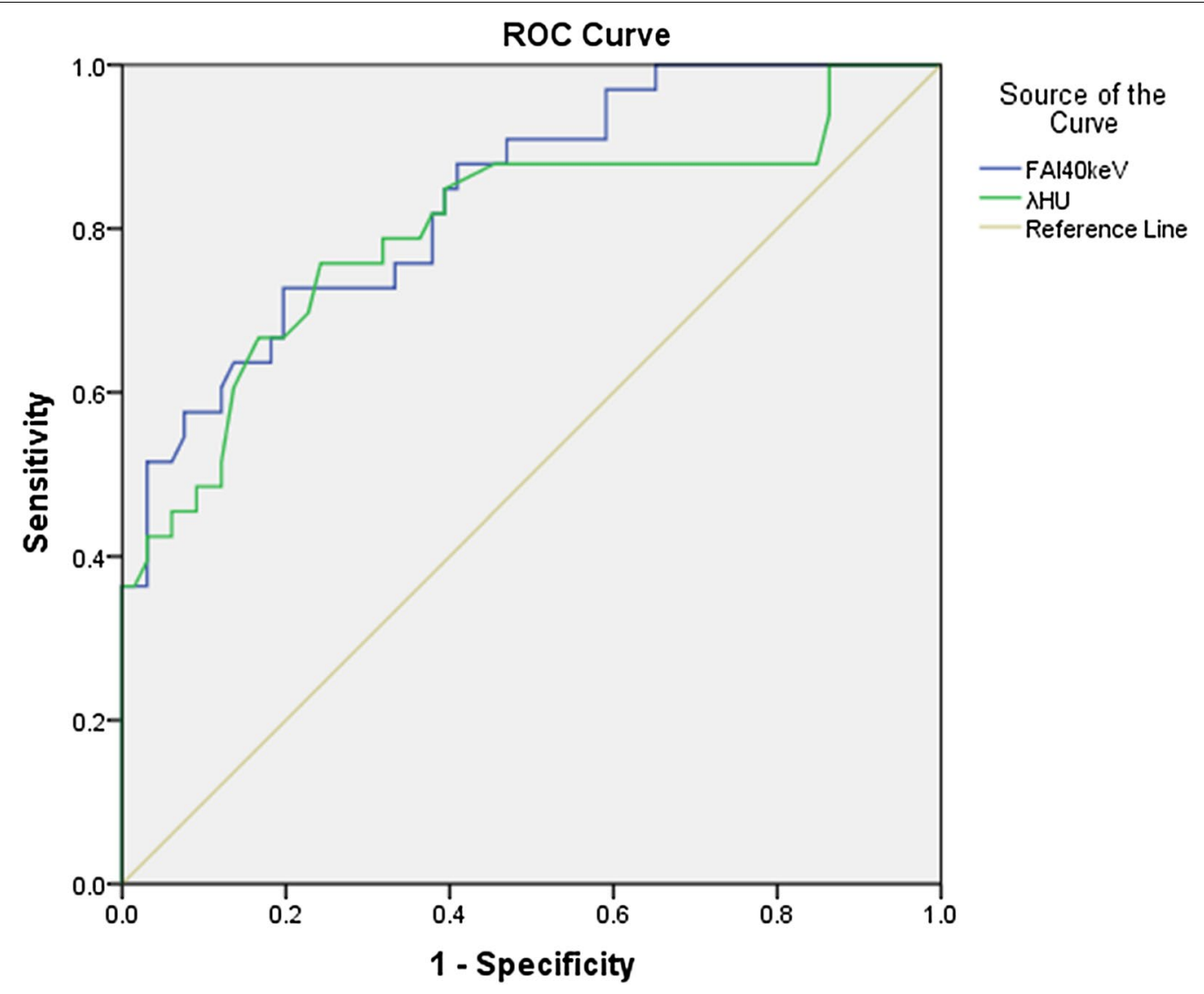

Fig. 2 ROC analysis for prediction of significant stenosis

Table 4 Cut-off values of PCAT indices for the detection of significant stenosis

\begin{tabular}{|c|c|c|c|c|c|c|c|}
\hline Parameters & Cut-off value & AUC (95\% Cl) & Sensitivity (\%) & Specificity (\%) & $\begin{array}{l}\text { Positive } \\
\text { likelihood } \\
\text { ratio }\end{array}$ & $\begin{array}{l}\text { Negative } \\
\text { likelihood ratio }\end{array}$ & Accuracy (\%) \\
\hline $\mathrm{FAI}_{40 \mathrm{keV}}$ & -144.21 & $0.84(0.76-0.92)$ & 72.70 & 80.30 & 3.69 & 0.34 & 81.80 \\
\hline$\lambda_{\mathrm{HU}}$ & 1.55 & $0.80(0.70-0.90)$ & 75.80 & 75.80 & 3.13 & 0.32 & 75.70 \\
\hline Z value & & 0.081 & & & & & \\
\hline$P$ value & & 0.936 & & & & & \\
\hline
\end{tabular}

PCAT = pericoronary adipose tissue $; \mathrm{Cl}=$ confidence interval

significantly different from those in non-significant stenosis group and significant stenosis group. In addition, this study showed that FAI40keV and $\lambda \mathrm{HU}$ are independent predictors of significant stenosis. This prompted PCAT attenuation may provide a surrogate global biomarker for underlying vascular inflammation importantly [19]. Some studies have shown that the EFV of patients with cardiovascular disease is related to the severity of the disease [20], and the EFV of patients with coronary heart disease is larger than patients without coronary heart disease [21], however some clinical studies did not find a significant correlation between the EFV and the severity of coronary artery stenosis [22], which is consistent with the results of this present study. This may indicate that in the process from subclinical atherosclerosis to non-significant stenosis, the increase in EFV has a better warning effect on atherosclerosis than the PCAT indicators, and EFV will help identify people at high risk of atherosclerosis. This just makes up for the relatively insensitive 
shortcoming of PCAT indicators in the early stage of the disease.

The small sample size was a limitation of our study and there is a bias in the selection of retrospective studies. Therefore, a large randomized controlled study remain to be done in the future. We did not include patients with high-risk plaques considering the impact of high-risk plaque on PCAT. In addition, we did not compare the value of FAI on conventional CT and SDCT in the diagnosis of vascular stenosis. We did not measure the effect of different measurement points to our findings.

In conclusion, the PCAT parameters of SDCT changed with the change of stenosis. FAI40kev and $\lambda \mathrm{HU}$ were independent risk factors for significant coronary artery stenosis. SDCT may provide alternative imaging markers for potential vascular inflammation, which may help indicate the degree of disease progression.

\begin{abstract}
Abbreviations
PCAT: Pericoronary adipose tissue; SDCT: Spectral detector CT; FAI: Fat attenuation index; $\lambda \mathrm{HU}$ : Spectral curve slope; Eff-Z: Effective atomic number; CAD: Coronary artery disease; EAT: Epicardial adipose tissue; MRI: Magnetic resonance imaging; MSCT: Multi-slice spiral CT; EFV: Epicardial fat volume; CTA : Computed tomography angiography; ECG: Electrocardiogram; DRI: Dose right index; ROI: Region of interest; HR: Heart rate; SBI: Spectral-based image; DS: Diameter stenosis; VMI: Virtual mono-energetic images; CAG: Coronary angiography.
\end{abstract}

\section{Acknowledgements}

None.

\section{Authors' contributions}

$X Z, Y H$ and $X C$ participated in the design of the study and performed the statistical analysis. XZ, XC, SM, KZ and YH conceived of the study, and participated in its design and coordination and helped to draft the manuscript. All authors read and approved the final manuscript.

\section{Funding}

This study was granted by the key Research \& Development Plan of Liaoning Province (No. 2020JH2/10300037) and 345 Talent Project in Shengjing Hospital of China Medical University.

\section{Availability of data and materials}

Data sharing not applicable to this article as no datasets were generated or analysed during the current study.

\section{Declarations}

Ethics approval and consent to participate

The study was approved by the ethics committee of Shengjing Hospital of China Medical University (2020PS231K).

\section{Consent for publication}

All patients had signed informed consent forms.

\section{Competing interests}

The authors declare that they have no competing interests.

\section{Author details}

'Department of Radiology, Key Laboratory of Intelligent Computing in Medical Image, Ministry of Education, Shengjing Hospital of China Medical University, No.36, Sanhao Street, Heping District, Shenyang 110004, Liaoning, People's Republic of China. ${ }^{2}$ Department of Medical Imaging, The First
Affiliated Hospital of Hebei North University, Zhangjiakou 075000, People's Republic of China.

Received: 3 June 2021 Accepted: 29 October 2021

Published online: 07 November 2021

\section{References}

1. Cho JH, Kim HL, Kim MA, Oh S, Kim M, Park SM, et al. Association between obesity type and obstructive coronary artery disease in stable symptomatic postmenopausal women: data from the KoRean wOmen'S chest pain rEgistry (KoROSE). Menopause (New York, NY). 2019;26(11):1272-6. https://doi.org/10.1097/gme.0000000000001392.

2. Packer M. Epicardial adipose tissue inflammation can cause the distinctive pattern of cardiovascular disorders seen in psoriasis. Am J Med. 2020;133(3):267-72. https://doi.org/10.1016/j.amjmed.2019.08.027.

3. Nagayama Y, Nakamura N, Itatani R, Oda S, Kusunoki S, Takahashi H, et al. Epicardial fat volume measured on nongated chest $\mathrm{CT}$ is a predictor of coronary artery disease. Eur Radiol. 2019;29(7):3638-46. https://doi.org/ 10.1007/s00330-019-06079-x.

4. Guglielmo M, Lin A, Dey D, Baggiano A, Fusini L, Muscogiuri G, et al. Epicardial fat and coronary artery disease: Role of cardiac imaging. Atherosclerosis. 2021;321:30-8. https://doi.org/10.1016/j.atherosclerosis. 2021.02.008.

5. Antonopoulos AS, Sanna F, Sabharwal N, Thomas S, Oikonomou EK, Herdman $L$ et al. Detecting human coronary inflammation by imaging perivascular fat. Science translational medicine. 2017;9(398). https://doi. org/10.1126/scitranslmed.aal2658

6. Nicol ED, Norgaard BL, Blanke P, Ahmadi A, Weir-McCall J, Horvat PM, et al. The future of cardiovascular computed tomography: advanced analytics and clinical insights. JACC Cardiovasc Imaging. 2019;12(6):1058-72. https://doi.org/10.1016/j.jcmg.2018.11.037.

7. Nakaura T, Oda S, Utsunomiya D, Tokuyasu S, Yamashita Y. Dual-layer computed tomography in cardiovascular imaging. Cardiovasc Imaging Asia. 2018;2(2):49.

8. Eagle KA, Guyton RA, Davidoff R, Edwards FH, Ewy GA, GardnerTJ, et al. ACC/AHA 2004 guideline update for coronary artery bypass graft surgery: a report of the American College of Cardiology/American Heart Association Task Force on Practice Guidelines (Committee to Update the 1999 Guidelines for Coronary Artery Bypass Graft Surgery). Circulation. 2004;110(14):e340-437.

9. Kaur M, Rahimi R, Razali F, Mohd Noor N, Omar E, Abdul Manaf Z, et al. Association of coronary artery calcium score with calcification and degree of stenosis: an autopsy study. Malays J Pathol. 2019;41(2):177-83.

10. Tan $Y$, Zhou J, Zhou Y, Yang $X$, Wang J, Chen Y. Epicardial adipose tissue is associated with high-risk plaque feature progression in non-culprit lesions. Int J Cardiovasc Imaging. 2017;33(12):2029-37. https://doi.org/10. 1007/s10554-017-1158-3.

11. Oikonomou EK, Marwan M, Desai MY, Mancio J, Alashi A, Hutt Centeno E, et al. Non-invasive detection of coronary inflammation using computed tomography and prediction of residual cardiovascular risk (the CRISP CT study): a post-hoc analysis of prospective outcome data. Lancet (London, England). 2018;392(10151):929-39. https://doi.org/10.1016/s01406736(18)31114-0.

12. Rodriguez-Granillo GA, Capunay C, Deviggiano A, De Zan M, Carrascosa P. Regional differences of fat depot attenuation using non-contrast, contrast-enhanced, and delayed-enhanced cardiac CT. Acta Radiol (Stockholm, Sweden: 1987). 2019;60(4):459-67. https://doi.org/10.1177/ 0284185118787356.

13. Goeller M, Achenbach S, Marwan M, Doris MK, Cadet S, Commandeur F, et al. Epicardial adipose tissue density and volume are related to subclinical atherosclerosis, inflammation and major adverse cardiac events in asymptomatic subjects. J Cardiovasc Comput Tomogr. 2018;12(1):67-73. https://doi.org/10.1016/j.jcct.2017.11.007.

14. Antoniades $C$, Antonopoulos AS, Deanfield J. Imaging residual inflammatory cardiovascular risk. Eur Heart J. 2020;41(6):748-58. https://doi.org/10. 1093/eurheartj/ehz474.

15. Ridker PM. From C-reactive protein to interleukin-6 to interleukin-1: moving upstream to identify novel targets for atheroprotection. Circ Res. 2016;118(1):145-56. https://doi.org/10.1161/circresaha.115.306656. 
16. Hell MM, Achenbach S, Schuhbaeck A, Klinghammer L, May MS, Marwan M. CT-based analysis of pericoronary adipose tissue density: Relation to cardiovascular risk factors and epicardial adipose tissue volume. J Cardiovasc Comput Tomogr. 2016;10(1):52-60. https://doi.org/10.1016/j. ject.2015.07.011.

17. Abazid RM, Smettei OA, Kattea MO, Sayed S, Saqqah H, Widyan AM, et al. Relation between epicardial fat and subclinical atherosclerosis in asymptomatic individuals. J Thorac Imaging. 2017;32(6):378-82. https://doi.org/ 10.1097/rti.0000000000000296.

18. Janik M, Hartlage G, Alexopoulos N, Mirzoyev Z, McLean DS, Arepalli CD, et al. Epicardial adipose tissue volume and coronary artery calcium to predict myocardial ischemia on positron emission tomography-computed tomography studies. J Nucl Cardiol Off Publ Am Soc Nucl Cardiol. 2010;17(5):841-7. https://doi.org/10.1007/s12350-010-9235-1.

19. Eisenberg E, McElhinney PA, Commandeur F, Chen X, Cadet S, Goeller $M$, et al. Deep learning-based quantification of epicardial adipose tissue volume and attenuation predicts major adverse cardiovascular events in asymptomatic subjects. Circ Cardiovasc Imaging. 2020;13(2):e009829. https://doi.org/10.1161/circimaging.119.009829.

20. Liu Z, Wang S, Wang Y, Zhou N, Shu J, Stamm C, et al. Association of epicardial adipose tissue attenuation with coronary atherosclerosis in patients with a high risk of coronary artery disease. Atherosclerosis. 2019;284:230-6. https://doi.org/10.1016/j.atherosclerosis.2019.01.033.

21. Gullaksen S, Funck KL, Laugesen E, Hansen TK, Dey D, Poulsen PL. Volumes of coronary plaque disease in relation to body mass index, waist circumference, truncal fat mass and epicardial adipose tissue in patients with type 2 diabetes mellitus and controls. Diab Vasc Dis Res. 2019;16(4):328-36. https://doi.org/10.1177/1479164119825761.

22. Tanami $Y$, Jinzaki M, Kishi S, Matheson M, Vavere AL, Rochitte CE, et al. Lack of association between epicardial fat volume and extent of coronary artery calcification, severity of coronary artery disease, or presence of myocardial perfusion abnormalities in a diverse, symptomatic patient population: results from the CORE320 multicenter study. Circ Cardiovasc Imaging. 2015;8(3):e002676. https://doi.org/10.1161/circimaging.114. 002676.

\section{Publisher's Note}

Springer Nature remains neutral with regard to jurisdictional claims in published maps and institutional affiliations.
Ready to submit your research? Choose BMC and benefit from:

- fast, convenient online submission

- thorough peer review by experienced researchers in your field

- rapid publication on acceptance

- support for research data, including large and complex data types

- gold Open Access which fosters wider collaboration and increased citations

- maximum visibility for your research: over $100 \mathrm{M}$ website views per year

At BMC, research is always in progress.

Learn more biomedcentral.com/submissions 